\title{
The Monitoring and Wireless Transmission System of PM2.5 in the Scenic
}

\author{
Wang Xiaohui \\ School of Leisure Management \\ Xi'an eurasia University \\ Xi'an, China \\ e-mail: wangxiaohui@eurasia.edu
}

\author{
Lei Kewei \\ School of Leisure Management \\ Xi'an eurasia University \\ Xi'an, China \\ e-mail: leikewei@eurasia.edu
}

\begin{abstract}
This Scenic area has large traffic volume and complex environment and some scenic areas need to be protected. So developing an air quality monitoring system is very important. In this paper, the temperature sensor, the PM2.5 sensor and the wireless transmission module were combined by the MCU. It monitors the spot in PM2.5 concentration and the temperature information. When the PM2.5 concentration is higher than the threshold, the wireless transmission module sends the warning signal. So the system could measure and improve the environment of scenic spot.
\end{abstract}

Keywords-PM2.5 Sensor; Dust Monitoring; Temperature Sensor; SIM900A

\section{INTRODUCTION}

With the rapid development of the industrial level, the air quality in daily life is getting worse. Especially when the people are densely poured into the scenic area, the ambient air quality is even worse[1]. Therefore, how to effectively collect the PM2.5 in the scenic core area and transmit data in time is a difficult problem to be solved[2].

In recent years, the minimum system is used in the dust monitoring with the advantages of small size, powerful function and the low cost[3]. So the application of the PM2.5 sensor and the wireless transmission system based on 89C51 board can ensure the physical and mental safety in the scenic area for the tourists.

\section{ANALYSIS OF THE SYSTEM ARCHITECTURE}

\section{A. System hardware architecture}

The system based on 89C51 single chip is composed of the data acquisition module, the key circuit, the alarm module and the GSM wireless transmission module. The structure of the system is shown in Figure 1.

As shown in Figure 1, the system can collect the PM2.5 and the temperature data in a certain area through the dust particle sensor and the temperature sensor. Because the analog signal could not processed by the MCU, so using DS1820 AD conversion module to convert the analog signal to the digital signal and then transmit the data to the MCU and displayed on the LCD screen. At the same time, the MCU compares the collected data with the threshold, if the collected value is higher than the threshold, the buzzer will alarm and send the PM2.5 concentration and the current temperature information to the user with the short message[4].

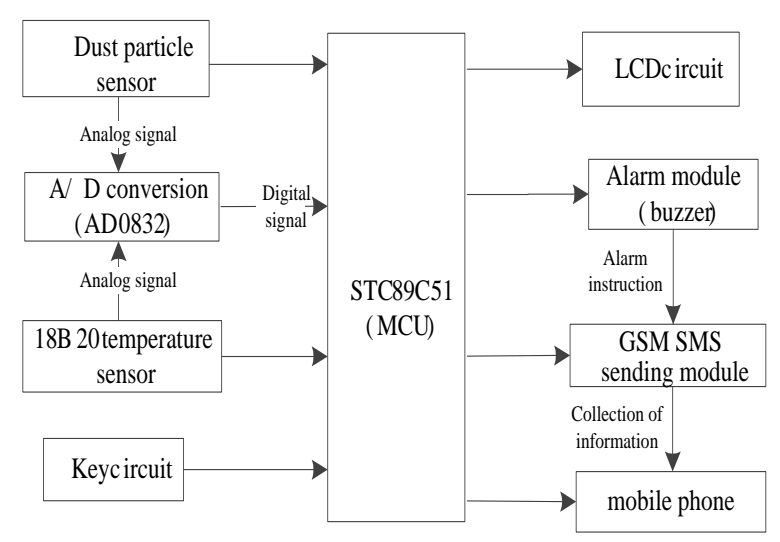

Figure 1. System structure diagram

\section{B. PM2.5 dust sensor module}

The selection of the PM2.5 dust sensor affects the range and precision of the monitoring module directly. GP2Y1010AU0F dust concentration sensor was used in this paper. From Table 1, the working voltage of the dust concentration sensor module is the same with the single chip. Its high accuracy meets the requirements of the majority of users. The large temperature range can be applied to all kinds of bad environment. In general, more than $120 \mathrm{mg} / \mathrm{m} 3$ of PM2.5 can cause harm to the human body, so this module's range is sufficient.

TABLE I. CHARACTERISTICS OF DUST CONCENTRATION SENSOR

\begin{tabular}{|c|c|c|c|}
\hline Characteristic & $\begin{array}{c}\text { Input Voltage } \\
(\mathbf{V})\end{array}$ & Current $(\mathbf{m A})$ & Precision $\left(\boldsymbol{\mu}_{\mathbf{m}}\right)$ \\
\hline Index & $4.98 \sim 5.02$ & $<20$ & 0.8 \\
\hline Characteristic & $\begin{array}{c}\text { Working } \\
\text { temperature }\left({ }^{\circ} \mathrm{C}\right)\end{array}$ & $\operatorname{Range}\left(\mathbf{m g} / \mathbf{m}^{\mathbf{3}}\right)$ & sensitivity \\
\hline Index & $-10 \sim+65$ & $0 \sim 0.8$ & $0.5 \mathrm{~V} / 0.1 \mathrm{mg}$ \\
\hline
\end{tabular}

Dust sensor is used to measure the dust concentration in the air by the reflection principle of dust. The internal structure of the dust concentration sensor is shown in Figure 2. 


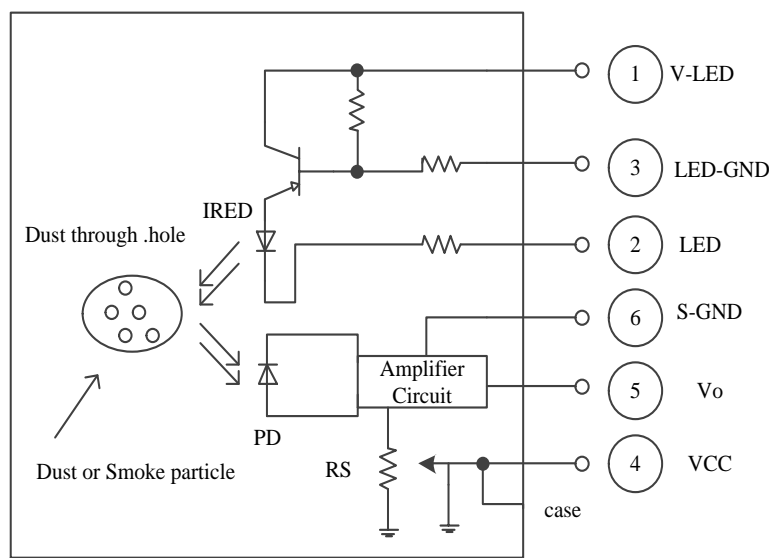

Figure 2. The structure of the dust concentration sensor

TABLE II. DUST SENSOR PIN

\begin{tabular}{|c|c|c|c|c|c|c|}
\hline PIN & $\mathbf{1}$ & $\mathbf{2}$ & $\mathbf{3}$ & $\mathbf{4}$ & $\mathbf{5}$ & $\mathbf{6}$ \\
\hline Description & $5 \mathrm{~V}$ & GND & Pulse & GND & $\begin{array}{c}\text { Output } \\
\text { Voltage }\end{array}$ & $5 \mathrm{~V}$ \\
\hline Function & \multicolumn{3}{|c|}{ Control the receiving PD } & \multicolumn{4}{|c|}{ Control the sending IRED } \\
\hline
\end{tabular}

The function and pin of the dust sensor is shown in Table 2 . With the received pulse signal and the output voltage signal from the single chip, the dust sensor controls the receiving device PD (photo detector). The sending device IRED (infrared light emitting diode) feeds the MCU with the dust concentration in the form of voltage. There are two transistors IRED and PD inside the dust sensor. The IRED emits the light and the PD receives the light signals reflected back by the dust. When the module works normally, the IRED emits the light. If the dust particle is enough, the reflected light will received by PD, the intensity of the light signal will change the PD voltage. Then with the higher output voltage of the dust particles, the concentration of PM2.5 becomes higher.

\section{DS1820 temperature sensor module}

A DS1820 digital thermometer provides nine bits (binary) temperature readings and the single chip can communicate with DS1802. Each DS1802 has a specific sequence number. Multiple DS1820 can work on the same bus without worrying lack of the bus. The pin of the DS1820 is shown in Figure 3:

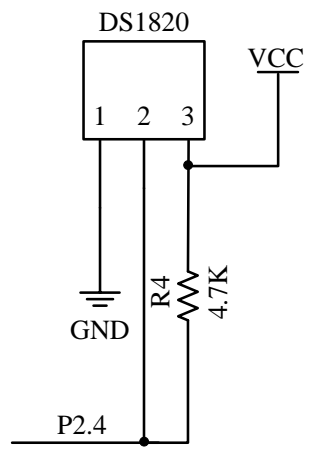

Figure 3. The pin of the DS1820
The measurement range of the DS1820 from $-55^{\circ} \mathrm{C}$ to $125^{\circ} \mathrm{C}$. Two eight bits temperature values were stored. The DS1820 has two power supply mode: data bus power supply mode and external power supply mode. The first mode uses less wire but less efficiency. The latter used a single wire but faster. The DS1820 interface specifications: pin one is the ground; pin two connects the single chip P2 for data transmission; pin three connects VCC.

DS1820 stored the with the nine bits temperature value. The highest bit is the symbol bit. The temperature storage of DS1820 is shown in Table3. When the temperature is negative $S=1$, when it is positive $S=0$. Such as: $00 \mathrm{AAH}$ indicates $+85^{\circ} \mathrm{C}, 0032 \mathrm{H}$ is $25^{\circ} \mathrm{C}$ and FF92 $\mathrm{H}$ is $-55^{\circ} \mathrm{C}$.

TABLE III. DS1820 STORAGE

\begin{tabular}{|c|c|c|c|c|c|c|c|c|}
\hline Bit & Bit7 & Bit6 & Bit5 & Bit4 & Bit3 & Bit2 & Bit1 & Bit0 \\
\hline $\begin{array}{c}\text { LS } \\
\text { Byte }\end{array}$ & $2^{\wedge} 7$ & $2^{\wedge} 6$ & $2^{\wedge} 5$ & $2^{\wedge} 4$ & $2^{\wedge} 3$ & $2^{\wedge} 2$ & $2^{\wedge} 1$ & $2^{\wedge} 0$ \\
\hline Bit & Bit15 & Bit14 & Bit13 & Bit12 & Bit11 & Bit10 & Bit9 & Bit8 \\
\hline $\begin{array}{c}\text { MS } \\
\text { Byte }\end{array}$ & S & S & S & S & S & S & S & S \\
\hline
\end{tabular}

\section{GSM wireless communication module}

GSM (Global system of mobile) is the second generation of the mobile communication technology. It promotes the globalization of the world and makes the users use one mobile phone to communicate around the world. So they produced a unified standard of the mobile phone network, namely the GSM. GSM wireless communication module adopts the SIMCOM's SIM900A module to realize the function of the short message.

The SIM900A module supports most $3 \mathrm{G}$ or $4 \mathrm{G}$ mobile communications services. The TTL serial port and the RS232 module can be used for debugging. The SIM900A module has the function of the power self-starter. Firstly, the SIM card is placed in the slot and then the working mode of the SIM900A is shown in Table 4:

TABLE IV. THE WORKING MODE OF THE SIM900A

\begin{tabular}{|c|c|c|}
\hline D5 & D6 & Working Status \\
\hline Long bright & quick flashing & Searching net \\
\hline Long bright & Slow flashing & Normal working \\
\hline Over & $\begin{array}{c}\text { lighting long and off } \\
\text { short }\end{array}$ & Low power \\
\hline Off & Slow flashing & Send RING \\
\hline $\begin{array}{c}\text { Off one time and } \\
\text { Long bright }\end{array}$ & Slow flashing & Receive one message \\
\hline
\end{tabular}

GSM module realizes the function of SMS through SIM900A chip controlling the SIM card module and other modules. Nowadays it is widely used in China.

\section{E. Design the system software}

At first, the system initializes the flash, the port and the LCD etc[5]. Then the sensor begins work and the data collection is achieved. After the AD0832 converted, the data is displayed on the LCD1602. At this time, if the data is higher than the threshold, the buzzer alarms and the data is sent to the user's mobile phone through the GSM wireless 
transmission module to complete the alarm function[6]. The software process is shown in Figure 4.

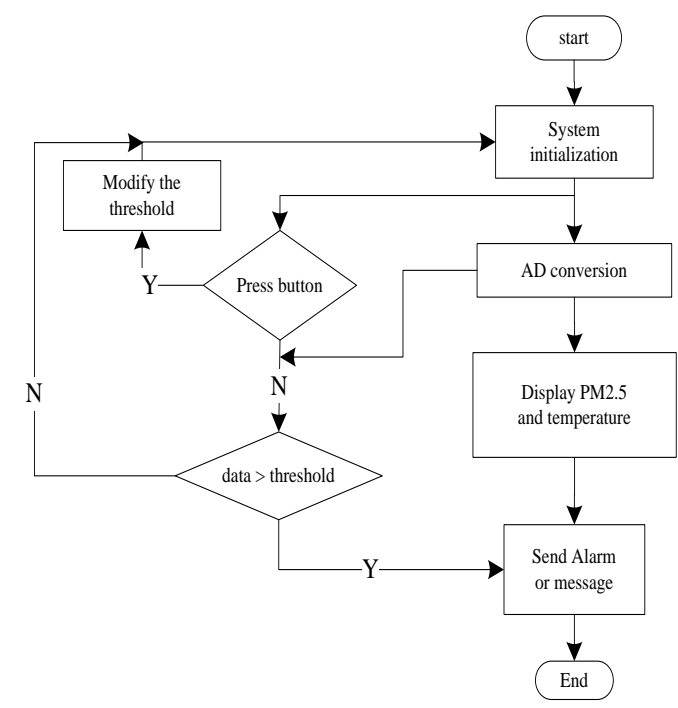

Figure 4. The flow chart of the system

\section{ACQUISITION AND TRANSMISSION}

\section{A. Data collection of the PM2.5}

The data collection of the dust concentration is the key of the software programming. The data collection and processing of PM2.5 concentration is introduced in Figure 5.

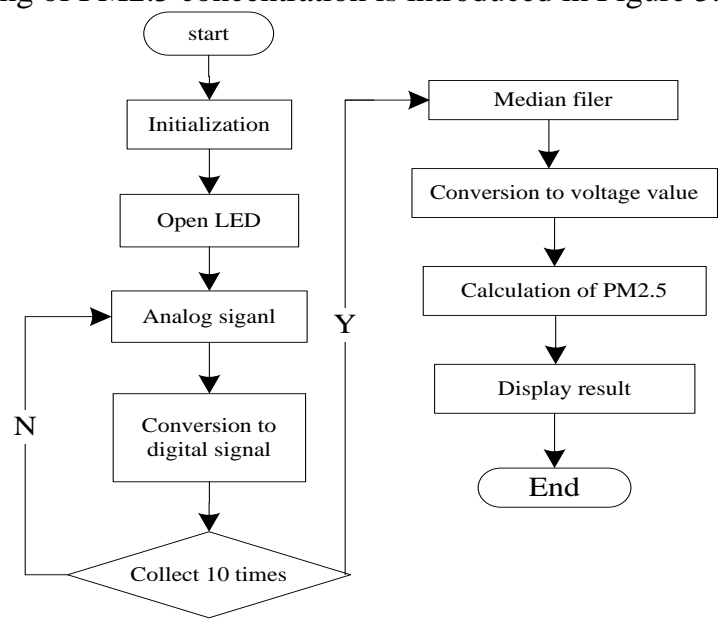

Figure 5. PM2.5 collection flow chart

When the power turns on, the dust monitoring sensor initializes[7]. Then the PM2.5 sensor is waiting for the instruction from the MCU. When it receives the instruction, the sensor turns on the IRED to data acquisition, PD (photo detector) will receive the reflected light signal, and the light intensity will affect the voltage across the PD, which is sent to the MCU[8]. After received the voltage signal, the MCU controls AD0832 begin A/D conversion and the collected information send to the LCD1602, so the data acquisition is completed.

\section{B. The temperature data collection}

The DS1820 temperature sensor collects the temperature and returns the digital information[9].As shown in Figure 6, After initialization, the sensor reads the data in ROM: the serial number and the temperature information of DS1820[10]. The general delay 1s can read the temperature information, and then the pointer in the buffer is added to the next data reading[11].

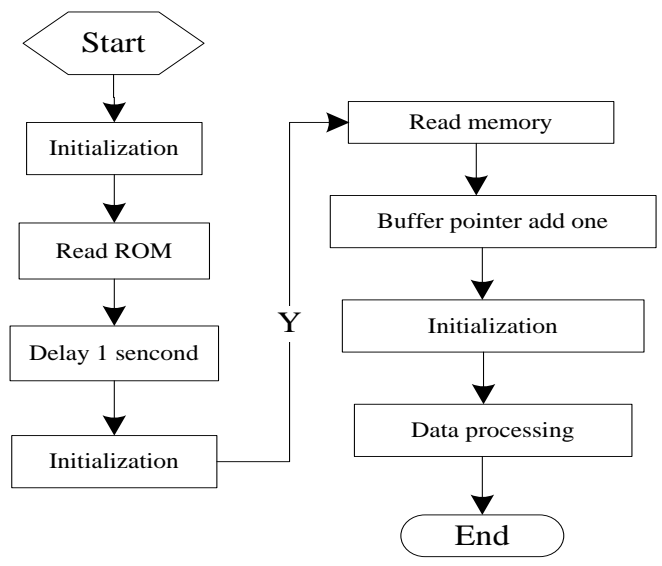

Figure 6. The flow chart of temperature collection

\section{SYSTEM TEST RESULTS}

The system platform is placed in the core area of the scenic area, and the sensor is opened to collect and transmit the surrounding environment parameters in real time[12]. The data collection is divided into two parts: the dust concentration acquisition and the temperature acquisition. As shown in Figure 7 (a), the LCD1602 LCD displays the temperature and PM2.5 concentration when the system is monitored. At this time the temperature is $26.8^{\circ} \mathrm{C}$, and the concentration of PM 2.5 is $0.029 \mathrm{mg} / \mathrm{m} 3$. The concentration threshold of the PM2.5 can be set by the key circuit and the PM2.5 concentration threshold is set to $0.120 \mathrm{mg} / \mathrm{m} 3$.

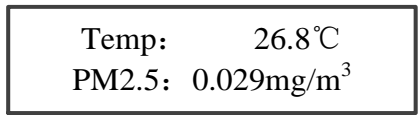

(a)

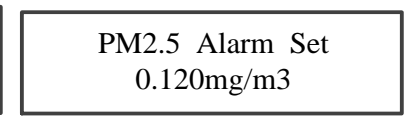

(b)
Figure 7. Data collection and concentration setting diagram

When the concentration of PM2.5 exceeds the threshold, the display information on the LCD1602 LCD screen is shown in Figure 8 (a). At present, the concentration of PM2.5 is $0.157 \mathrm{mg} / \mathrm{m} 3$, which exceeds the threshold $0.120 \mathrm{mg} / \mathrm{m} 3$, so the GSM wireless transmission module sends the alarm information to the user, as shown in Figure 6 (b). At this time, the user sees the PM2.5 concentration alarm. The temperature is $27.9^{\circ} \mathrm{C}$, and the concentration of PM2.5 is $0.157 \mathrm{mg} / \mathrm{m} 3$, which is the same as the alarm information on LCD1602 LCD screen. 


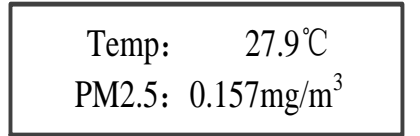

(a)

\section{PM2.5 alarm! T:27.9 ${ }^{\circ} \mathrm{C}$ P: $0.157 \mathrm{mg} / \mathrm{m}^{3}$}

Figure 8. System alarm and SMS

Through the monitoring system, the user can see the surrounding environmental parameters of the monitored area in time. So the problem of environmental monitoring in the scenic core area can be solved through the platform.

\section{CONCLUSIONS}

The monitoring system for the PM2.5 concentration and the real-time temperature is designed in this paper. The collected data was transmitted by the wireless transmission module based on the MCU. When the PM2.5 concentration is higher than a threshold, the buzzer alarms and the current environment information is sent to the mobile phone. Because the low cost and the highly performance characteristic, so it can be applied to the high-density areas.

\section{ACKNOWLEDGMENT}

This work was partly supported by Shaanxi Province Social Science Fund Project (NO.2016R022) of China and by the scientific research fund project of Shaanxi Provincial Department of Education (17JK1036).

\section{REFERENCES}

[1] G.Xu, X.Yang, and Q.Yang, et al. "Design on Magnetic Coupling R esonance Wireless Energy Transmission and Monitoring System for I mplanted Devices", IEEE Transactions on Applied Superconductivity, vol.26, Apr.2016, pp.1-4, doi:10.1109/TASC.2016.2524591J.

[2] R.Prakash, A.B.Ganesh, and S. V.Girish. "Cooperative wireless netw ork control based health and activity monitoring system", Journal of Medical Systems, vol.40, Oct.2016, pp.216, doi::10.1007/s10916-016 -0576-4.
[3] J. C.Heo, B.Kim, and Y. N.Kim, et al. "Induction of Inflammation In Vivo by Electrocardiogram Sensor Operation Using Wireless Power Transmission", Sensors, vol.17, Dec.2017, pp. 2905, doi:10.3390/s17 122905.

[4] T.Liang, Y.J.Yuan. "Wearable Medical Monitoring Systems Based on Wireless Networks: A Review", IEEE Sensors Journal, vol.16, Aug.2016, pp.186-8199, doi:10.1109/JSEN.2016.2597312.

[5] Q.Zheng, H.Zhang, and B.Shi, et al. "In Vivo Self-Powered Wireless Cardiac Monitoring via Implantable Triboelectric Nanogenerator", Ac s Nano, vol.10, Jul. 2016, pp.6510, doi:10.1021/acsnano.6b02693.

[6] G.Anfuso, A.T.Williams, and G.C.Martínez. "Evaluation of the scenic value of 100 beaches in Cuba: Implications for coastal tourism management", Ocean \& Coastal Management, vol.142, May. 2017, pp.173-185, doi:10.1016/j.ocecoaman.2017.03.029.

[7] S.Shi, Z.Wu, and F.Liu, et al. "Retention of Atmospheric Particles by Local Plant Leaves in the Mount Wutai Scenic Area, China", Atmosphere, vol.7, Aug. 2016, pp.104, Doi:10.3390/atmos7080104.

[8] P.Chen, Y.Q.Lian . "Modeling of soil loss and its impact factors in the Guijiang Karst River Basin in southern China", Environmental Earth Sciences, vol.75, Apr. 2016, pp.352, doi:10.1007/s12665-0165288-z.

[9] J.Guo, F.Xia, and Y.Zhang. "Impact of diurnal variability and meteorological factors on the PM2.5-AOD relationship: Implications for PM2.5 remote sensing", Environmental Pollution, vol.221, Nov.2017, pp.94, doi:10.1016/j.envpol.2016.11.043.

[10] S.Samiksha, R.R.Sunder, and Nirmalkar J. "PM10 and PM2.5 chemical source profiles with optical attenuation and health risk indicators of paved and unpaved road dust in Bhopal, India", Environmental Pollution, vol.222, Nov. 2017, pp.477-485. doi.org/10.1016/j.envpol.2016.11.067.

[11] S.K.R.Boreddy, T.Mochizuki , and Kawamura K, et al. "Homologous series of low molecular weight (C1-C10) monocarboxylic acids, benzoic acid and hydroxyacids in fine-mode (PM2.5) aerosols over the Bay of Bengal: Influence of heterogeneity in air masses and formation pathways", Atmospheric Environment, vol.167, Oct. 2017, pp.170-180, doi:10.1016/j.atmosenv.2017.08.008.

[12] H.M.Lee, R.J.Park, and Henze D K, et al. "PM2.5 source attribution for Seoul in May from 2009 to 2013 using GEOS-Chem and its adjoint model", Environmental Pollution, vol.31, Nov. 2017, pp.221.225, doi:10.1016/j.envpol.2016.11.088. 